\title{
O Pioneirismo Subversivo da Psicanálise nos Debates de Gênero e Sexualidade
}

\author{
Vinícius Moreira Lima ${ }^{1}$ \\ ${ }^{1}$ Universidade Federal de Minas Gerais, MG, Brasil.
}

\author{
Ângela Maria Resende Vorcaro ${ }^{2}$ \\ ${ }^{2}$ Universidade Federal de Minas Gerais, MG, Brasil.
}

Resumo: Nos debates contemporâneos da psicologia, muitas vezes a psicanálise é apressadamente descartada como um campo historicamente datado que se limitaria a promover uma reiteração de normas sociais pela reprodução de arranjos normativos de gênero e de orientação sexual. No entanto, neste trabalho, tentamos indicar alguns dos pontos de pioneirismo e de subversão da teoria psicanalítica em relação ao discurso médicomoral vigente à época de sua invenção e também em relação aos saberes contemporâneos sobre gênero e sexualidade. Isso não é feito sem o reconhecimento de alguns dos erros nos quais a psicanálise incorreu ao carregar consigo, em momentos variados, uma série de normatividades que lhe deveriam ser estranhas, mas que foram herdadas de modo acrítico de outros discursos que a antecederam. Assim, trata-se de investigar como a psicanálise permite pensar a sexualidade mais além da matriz sexo-gênero-orientação sexual, a fim de apontar formas de pioneirismo e subversão nas formulações de Freud e Lacan que podem contribuir para os debates de gênero e sexualidade, a partir do objeto $a$ e da teoria da sexuação.

Palavras-chave: Gênero, Sexualidade, Inconsciente, Objeto $a$, Sexuação.

\section{The Subversive Pioneer Nature of Psychoanalysis in discussion surrounding Gender and Sexuality}

\begin{abstract}
In contemporary debates within psychology, psychoanalysis is often discarded too hastily as a historically dated field of knowledge that would limit itself to promoting the reiteration of social norms, reproducing normative arrangements of gender and sexual orientation. Nevertheless, in this paper, we indicate how psychoanalysis was a subversive pioneer regarding the moral-medical discourse in force at the time of its invention and regarding the contemporary knowledge related to the fields of gender and sexuality. This is done by first acknowledging some of the mistakes made in psychoanalysis due to carrying a series of normativities that should be alien to it, but were heralded from other discourses in a rather uncritical manner. Thus, we investigate how psychoanalysis allows us to think sexuality beyond the matrix of sex/gender/sexual orientation, in order to point to manifestations of pioneering and subversion in Freud and Lacan's formulations that can contribute to discussion on gender and sexuality via the formulation of the objet petit $a$ and the theory of sexuation.
\end{abstract}

Keywords: Gender, Sexuality, Unconscious, Objet petit $a$, Sexuation. 


\title{
El Pionerismo Subversivo del Psicoanálisis en los Debates sobre Género y Sexualidad
}

\begin{abstract}
Resumen:En los debates contemporáneos dela psicología, el psicoanálisis es apresuradamente descartado muchas veces como un campo históricamente datado que se limitaría a promover la reiteración de normas sociales por la reproducción de arreglos normativos de género y de orientación sexual. Pero, en este trabajo intentamos indicar algunos de los puntos de pionerismo y de subversión de la teoría del psicoanálisis en relación al discurso médico-moral vigente a la época de su invención y también en relación a los discursos contemporáneos sobre género y sexualidad. Eso no está hecho sin reconocer algunos de los errores en los cuales el psicoanálisis incurrió al traer consigo, en momentos variados, una serie de normatividades que deberían ser extrañas, pero las heredó de modo acrítico de otros discursos anteriores a él. Se trata aquí de investigar cómo el psicoanálisis nos permite pensar la sexualidad más allá de la matriz sexo-género-orientación sexual, a fin de apuntar formas de pionerismo y subversión en las formulaciones de Freud y Lacan que pueden contribuir a los debates de género y sexualidad, a partir de la formulación del objeto $a$ y de la teoría de la sexuación.
\end{abstract}

Palabras clave: Género, Sexualidad, Inconsciente, Objeto $a$, Sexuación.

\section{Introdução}

Não é novidade alguma notar os avanços políticos trazidos pelos movimentos protagonizados por minorias sociais no século $\mathrm{XX}$, em especial o feminismo, lutando pelos direitos de emancipação das mulheres, e os coletivos LGBT, defendendo o reconhecimento de grupos sexuais que não se enquadram na categorização heterossexual (no caso dos gays, das lésbicas e dos bissexuais) e/ou se posicionam como transexuais ou travestis. Essas lutas pleiteavam, entre inúmeras pautas, a igualdade de direitos civis entre homens e mulheres, a possibilidade de existência pública de pessoas LGBT, o reconhecimento jurídico de pessoas trans pela retificação do nome social, além de um combate às violências perpetradas em nome dessas diferenças: feminicídio, homofobia, lesbofobia, bifobia e transfobia.

Um dos efeitos visíveis dessas lutas tem sido um profundo questionamento da hegemonia heterossexual e cisgênero, mesmo que ainda hoje seja necessária a resistência contra setores sociais conservadores que, geralmente embasados em pressupostos religiosos, insistem em reproduzir modelos normativos de organização do gênero e da sexualidade apoiados nos ideais do casamento e da reprodução heterossexual, bastiões de uma pretensa normalidade psíquica que seria garantida pela ordem divina. Na linha de frente contra esses setores, encontramos, na psicologia contemporânea (Conselho Regional de Psicologia Bahia, 2019), a importante distinção entre sexo, identidade de gênero e orientação sexual. Sua importância é no sentido de romper com exigências normativas de coerência e unidade entre anatomia, gênero, desejo e práticas sexuais, tradicionalmente orientadas a partir de uma heterossexualidade compulsória, numa contestação que serve tanto aos movimentos de emancipação feminina quanto aos de despatologização e reconhecimento de práticas e identidades LGBTQIA+.

Assim, a exemplo do que encontramos no glossário de uma cartilha produzida pelo Conselho Regional de Psicologia da Bahia (2019, pp. 14-15), os saberes contemporâneos sobre gênero e sexualidade se dedicam a sustentar a distinção entre: a) o sexo anatômico, isto é, a genitália com a qual o sujeito nasce por determinações biológicas (pênis, vagina ou intersexo); b) a identidade de gênero, relativa à identificação de cada sujeito a um gênero ou a outro, isto é, se o sujeito se reconhece como homem, como mulher 
ou como distinto dessas categorias binárias ${ }^{1}$; e c) a orientação sexual, que diz respeito às formas de atração que cada sujeito sente em relação aos outros, listadas como homossexual, heterossexual, bissexual, assexual, entre diversas outras formas possíveis, sem se tratar de uma escolha consciente ou voluntariosa.

Essa definição da matriz sexo-gênero-orientação sexual desempenha uma função política decisiva, pois, ao operar com tais nomeações, esse discurso "problematiza o que até então era tomado como natural e evidente" (Ambra, 2016, p. 104), fazendo aparecer a contingência dos discursos hegemônicos sobre a sexualidade. Ademais, se o grave silêncio dos universais ajuda a invisibilizar o caráter violento com que suas normas se impõem, $o$ ato de nomear se torna "um ato político por excelência", ao confrontar o sujeito com "um questionamento sobre sua posição no discurso do Outro" (Ambra, 2016, p. 104).

No embrião de uma série dessas leituras, encontramos o discurso da psicanálise, inaugurado por Sigmund Freud na virada do século XX, a partir de seus vastos estudos sobre o inconsciente. No entanto, nos debates contemporâneos da psicologia sobre as questões de gênero e sexualidade, muitas vezes a teoria psicanalítica é apressadamente descartada, por ser tomada como um campo historicamente datado, a favor da reprodução de arranjos normativos de gênero e de orientação sexual. Nesse contexto, nosso trabalho pretende indicar alguns dos pontos de pioneirismo e de subversão da psicanálise em relação ao discurso médico-moral vigente à época de sua invenção e também em relação aos saberes contemporâneos sobre gênero e sexualidade.

Isso não será feito sem reconhecermos alguns dos erros nos quais a psicanálise incorreu, ao carregar consigo, em momentos variados, uma série de normatividades que lhe deveriam ser estranhas, mas que foram herdadas de modo acrítico de outros discursos que a antecederam. Assim, trata-se de investigar como a psicanálise permite pensar a sexualidade mais além da matriz sexo-gênero-orientação sexual, a fim de apontar, nas formulações de Freud e Lacan, contribuições para os debates de gênero e sexualidade, a partir do objeto $a$ e da teoria da sexuação. Para tanto, nos apoiaremos em alguns dos ensinamentos da clínica psicanalítica, orientada pela singularidade do inconsciente.

\section{A herança de Freud}

A invenção da psicanálise, que podemos datar da virada para o século XX, é protagonizada por Freud, um médico neurologista que recebe, como herança de um dispositivo de sexualidade médico-moral, todo um corpo de terminologias e enquadres nosológicos com forte teor patologizante, orientado por uma norma reprodutiva heterossexual como ideal suposto de certa normalidade psíquica. Em oposição às discussões sobre a sexualidade que até então vigoravam na psiquiatria de um ponto de vista do instinto (Instinkt), Freud irá fazer seus contrapontos e contribuições especialmente a partir do conceito de pulsão (Trieb).

Esse conceito, apesar de, em alguns momentos, apresentar continuidades terminológicas com formas normativas dos discursos psiquiátricos da época, foi o pivô freudiano para pensar a sexualidade mais além de uma norma instintiva, que seria da ordem do natural ou do dado. Ao contrário de um instinto, a pulsão não tem um objeto pré-determinado; ela depende da montagem de um circuito a partir da história libidinal singular de um sujeito, levando Freud (1905/1996) a dizer que, entre a pulsão e o objeto, não há ligação natural ou necessária, mas apenas uma "solda" (p. 140). Essa formulação é correlata à posição de que o alvo da pulsão não é a reprodução sexuada, mas a sua própria satisfação, isto é, a reprodução de seu próprio circuito pulsional, a repetição de um mesmo circuito de satisfação.

Nesse sentido, como resume Zupančič (2008, p. 313), a sexualidade humana seria um desvio constitutivo de uma norma que não existe. Assim, se se trata de um desvio que é inerente ao campo do alvo e do objeto sexual, a psicanálise se mostra, desde cedo, afinada com um duplo processo de desnaturalização e despatologização da sexualidade - processo que localizamos na dimensão de uma satisfação à revelia do instinto, da reprodução e da genitalidade e também na dimensão de uma escolha de objeto em nível inconsciente, já que se trata de uma escolha realizada pela pulsão e não pelo eu do sujeito, sendo que, para a satisfação pulsional, a atividade da própria pulsão

\footnotetext{
${ }^{1}$ Entram aí, por exemplo, as travestis, o gênero fluido, o não-binário, genderfuck, genderless, entre várias outras modalidades, podendo essa identidade contrariar aquela que supostamente derivaria do sexo dito biológico - configurando uma transexualidade/transgeneridade. Inversamente, quando esse reconhecimento é conforme à designação dada a partir do sexo de nascença, o sujeito é dito cisgênero.
} 
é mais importante que o objeto ao qual ela se liga (Freud, 1905/1996, p. 140).

Sabemos, no entanto, que, na obra freudiana, houve a manutenção de uma série de terminologias comprometidas com o discurso patologizante da psiquiatria do século XIX, como os termos "normal" e "invertido" e a categoria da perversão. Mas sabemos, também, que os destinos psicanalíticos dessas terminologias subvertem profundamente o emprego regulador dado a essas categorias pela medicina moderna (Quinet, 2016). Ainda assim, persiste a necessidade do que Quinet (2016) chamou de "uma crítica assídua para que a psicanálise não seja degradada e engolida pela religião, ciência ou discurso capitalista" (p. 197). Pois, mesmo que o campo freudiano se coloque, desde o princípio, como um saber subversivo em relação à norma, ele também pode, por vezes, recair em posições conservadoras ou reprodutoras de arranjos normativos (Ambra, 2016, p. 106).

À guisa de exemplo, é notável o fato de que, por mais que Freud (1905/1996) tenha se referido à homossexualidade como uma "inversão de objeto" ou aos homossexuais como "invertidos", foi o mesmo psicanalista que escreveu uma carta de resposta, em 1935, a uma mãe americana que lhe interpelava demandando uma cura da homossexualidade de seu filho, dizendo a ela que essa escolha de objeto "não é nenhum vício, nenhuma degradação, não pode ser classificada como doença" (Freud, 1935/2018, p. 349), de modo que tampouco poderia ser "curada". Considerando a conjuntura histórica dessa posição freudiana, é inegável seu caráter de pioneirismo subversivo no campo psicanalítico - o que, entretanto, não nos exime do fato de que “o analista está tão exposto quanto qualquer outro a um preconceito relativo ao sexo, a despeito do que lhe revela o inconsciente" (Lacan, 1960/1998a, p. 740).

Podemos também constatar com surpresa a distinção pioneira que Freud realizou em um artigo datado de 1920 em relação ao que, hoje, chamamos de sexo, gênero e orientação sexual, a partir de seus estudos clínicos sobre a homossexualidade. Tratava-se, mesmo que pontualmente, de uma psicanálise profundamente subversiva em relação aos discursos de sua época, ao afirmar que "Caracteres sexuais somáticos (hermafroditismo físico)", "caráter sexual psíquico (posição masculina ou feminina)" e "tipo de escolha de objeto" são três componentes que variam entre si de maneira independente um do outro, em "permutações múltiplas” numsujeito (Freud, 1920/2017,pp.187-188).
Freud (1920/2017) acrescenta ainda que foi uma "literatura tendenciosa" que "dificultou o entendimento dessas proporções” (p. 188), ao colocar em primeiro plano a escolha de objeto e, em seguida, aproximá-la exageradamente à anatomia, como se houvesse uma cola necessária entre nascer com uma genitália específica e daí derivar uma determinada orientação sexual, de caráter heterossexual.

Mais do que isso, o movimento do raciocínio freudiano costuma seguir na direção de restituir ao universal aquilo que era localizado no campo do patológico, isto é, de pôr em evidência o comprometimento de todos os sujeitos com uma série de elementos que eram, até então, situados pela psiquiatria da época como manifestação excepcional de certa anormalidade psíquica, do campo do desviante (Van Haute \& Geyskens, 2016). Isso fica visível, por exemplo, quando lemos, em Freud (1920/2017), que "todos os normais, ao lado de sua heterossexualidade manifesta, deixam notar uma medida considerável de homossexualidade latente ou inconsciente" (p. 188), em que pese aí o emprego do termo "normais" como resquício da terminologia psiquiátrica vigente.

Ainda assim, ao considerar que todo sujeito apresenta tanto traços heterossexuais quanto homossexuais, sejam eles manifestos ou latentes, Freud está reconhecendo na libido seu caráter radicalmente contingencial a respeito das escolhas de objeto, ao sustentar sua teoria de uma bissexualidade psíquica que faz dissolver distinções rígidas ou naturalizantes entre homens e mulheres, "como se o indivíduo não fosse nem homem nem mulher, e sim ambos a cada vez, só que com mais de um do que do outro" (Freud, 1933/2018, p. 315). Dessa maneira, "a proporção a partir da qual o masculino e o feminino se mesclam no indivíduo sofre oscilações extraordinárias" (p.315), com o resultado de que aquilo que constitui a masculinidade ou a feminilidade "é uma característica desconhecida, que a anatomia não consegue apreender" (p. 316).

Tendo isso em mente, fica claro que, mesmo sustentando o uso da terminologia "masculino" e "feminino", inúmeros foram os momentos em que Freud suspeitou de sua substancialidade (Freud, 1920/2017, p. 189). Esses dois termos, que desvanecem se olhados de perto, não passariam de meras "construções teóricas de conteúdo incerto” (Freud, 1905/1996, p. 286), cujo uso seria sempre uma concessão ou à anatomia ou às convenções sociais (Freud, 1933/2018, p. 316). 
Ademais, 16 anos antes de Simone de Beauvoir publicar O segundo sexo, encontramos também uma incisiva afirmação freudiana, segundo a qual a psicanálise não quer "descrever o que a mulher é", mas sim "pesquisar como ela se torna mulher, como se desenvolve a partir da criança dotada de disposição bissexual" (p. 318).

Apesar disso, também é inegável o alcance limitado da leitura freudiana dos destinos da feminilidade, que, em sua forma bem-sucedida, para Freud, levaria à maternidade (Miller, 2010). Essa concepção estava atrelada a uma visão estreita da sexualidade feminina como se ela estivesse toda regida pela égide do falo, algo que foi duramente criticado por uma série considerável de escritoras feministas ao longo do século XX, a exemplo de Beauvoir (1949/1989) e Butler (1990/2015), e também por Lacan (197273/2008). Vemos, portanto, que a herança de um dispositivo médico-moral na psicanálise não ficou sem marcas na história do campo freudiano.

E isso não apenas nos textos de seu fundador, mas também no de importantes seguidores como Sándor Ferenczi, que, bem cedo, em 1911, esteve próximo de uma outra distinção pioneira no tocante à transexualidade, mas que se viu colonizado por um indiscutível ranço patologizante. Ao fazer a diferenciação entre um "homoerotismo de sujeito" e um "homoerotismo de objeto", Ferenczi (1911/1992) reserva ao segundo termo a ideia de uma "inversão" na escolha do objeto sexual, ao passo que, no primeiro termo, a dita "inversão" seria realizada na posição do sujeito mesmo, o que, em se tratando de 1911, antecipa consideravelmente a conceituação da transexualidade, que só surgiria próximo à metade do século $\mathrm{XX}$ - sob a rubrica patologizante do transexualismo.

Antecipação na medida em que esse homoerotismo "por inversão de sujeito" diria respeito a um homem "que se sente mulher em suas relações com os homens", sendo ele "invertido" quanto ao seu próprio eu, de maneira que o sujeito "se sente mulher não só durante as relações sexuais, mas em todas as demais relações de sua existência" (Ferenczi, 1911/1992, p. 119). No entanto o autor, apesar de estar surpreendentemente perto de um ponto subversivo, logo irá recair numa antiga confusão, ainda atual, entre homens cisgêneros homossexuais afeminados e mulheres transexuais, colocando em uma só categoria esses dois tipos de sujeito. Faltavam a Ferenczi as noções de identidade de gênero e papel de gênero para isolar as diferenças entre essas duas posições.
Nesse mesmo texto, Ferenczi (1911/1992) ainda se refere a suas tentativas (evidentemente, falhadas) de curar homossexuais de suas escolhas de objetos. Por isso, convém lembrar a afirmação de Ambra (2016) de que a psicanálise é "não-toda subversiva" (p. 106 , grifos do autor), com a consequência de ela estar sempre situada entre a possibilidade da subversão e o risco da reiteração da norma - donde a importância fundamental da crítica incessante de si mesma que devemos sustentar dentro do campo psicanalítico.

\section{Os destinos de Jacques Lacan}

Ainda que a genialidade de Freud tenha permitido a invenção da psicanálise, talvez seja em parte a radicalidade da intervenção de Lacan o que faz com que esse campo exista ainda hoje. Considerando a relevância da obra lacaniana na história do movimento psicanalítico, buscaremos, nesta seção, pinçar algumas de suas possíveis contribuições para os debates contemporâneos de gênero e sexualidade seguindo o rastro das colocações de Freud. Tal como a obra deste último, o trabalho de Lacan é permeado de tensões, que geram diferentes recepções por parte de seus leitores e leitoras.

Em meio a tantas críticas que o psicanalista francês recebeu, gostaríamos de salientar aqui, pela relevância temática para este artigo, as discussões de Jane Gallop, Judith Butler, Márcia Arán e Patricia Porchat, que, cada uma a sua maneira, intervêm criticamente em relação às leituras de Lacan para apontar a permanência de concepções normativas em sua obra. Fazendo um apanhado de algumas das questões que elas levantam, podemos mencionar o problema irresoluto da distinção entre falo e pênis (Gallop, 1988/2001), a ordem simbólica como a reificação de normas binárias de gênero (Butler, 1990/2015), a teoria da sexuação como reflexo de uma visão masculinista do feminino (Arán, 2009) e a terminologia lacaniana de "homem" e "mulher" como normativa, restringindo as possibilidades de vida de gêneros não-inteligíveis, do campo do abjeto (Porchat, 2014).

Sem desconsiderar essas críticas, o que nos interessa neste trabalho é localizar alguns dos pontos da obra de Lacan que possam contribuir para os debates contemporâneos de gênero e sexualidade, especialmente a partir da formulação do objeto $a$ e da tábua da sexuação. Esse exercício será feito na esteira de autores que já têm buscado levar em conta esse tipo de crítica dentro de um referencial lacaniano, a exemplo 
dos trabalhos de Ambra (2016), Quinet (2016), van Haute e Geyskens (2016), Lima (2018) e Cossi (2018).

Partindo das referidas críticas feministas, é preciso considerar que, principalmente no começo da década de 1950, Lacan flerta com a reiteração de certa norma fálica, por exemplo, ao falar sobre o caráter estruturante da identificação ao "tipo ideal de seu sexo" (Lacan, 1958/1998, p. 692), que projetaria na comédia "as manifestações ideais ou típicas do comportamento de cada um dos sexos" (p. 701). Nesse ponto de seu ensino, parece haver uma relação pouco desdobrada pelo autor entre as diferentes declinações do gênero e as formas de relação ao falo. É particularmente a esse respeito que Butler (1990/2015) endereça uma crítica decisiva, ao sugerir que a ordem simbólica lacaniana obrigaria os homens a encenarem a posição cômica de "ter o falo", e as mulheres, a posição de "ser o falo", sem possibilidade de subversão desse arranjo heterossexual. Entretanto, à medida que os estudos de Lacan vão avançando, podemos observar uma progressiva relativização dessa norma fálica, ao privilegiarem cada vez mais a dimensão da invenção singular de cada sujeito para lidar com o sem sentido do gozo.

Esse avanço é consequência de um movimento protagonizado por Lacan no sentido de recusar qualquer leitura de Freud que enxergue ali a presença do instinto. Fazendo duras críticas a esse tipo de postura moralista, o psicanalista francês enfatizará a montagem pulsional como sendo articulada por um circuito de significantes, os quais vêm contornar um objeto que excede a linguagem (o objeto $a$ ), tendo como paradigma o caso relatado por Freud (1927/2017) de um paciente que só conseguia sentir atração por mulheres em quem ele percebesse certo "brilho no nariz” (p. 315). Esse elemento se fez presente por uma homofonia, que marcou a infância do paciente, entre um "olhar [glance] para o nariz" (a partir de uma fala da governanta anglófona que dele cuidou) e o alemão "Glanz [brilho] auf der Nase".

Assim, esse sujeito constituiu o nariz como um fetiche a partir de um "brilho particularmente luminoso que os outros não podiam perceber” (Freud, 1927/2017, p. 316). Esse exemplo nos interessa por quatro aspectos. Primeiro, porque reencontramos aí a estratégia freudiana de restituir ao universal um elemento tido até então como exclusivamente patológico, ao considerar que o fetichismo, ao contrário de uma anormalidade, está presente, mesmo que pontualmente, em toda sexualidade humana, conferindo-lhe um caráter inegavelmente perverso e apontando para a persistência do infantil na vida do sujeito - infantil este que é compreendido como sexualidade perverso-polimorfa (Freud, 1905/1996).

Segundo, porque esse exemplo, ao sinalizar o valor fundamental do significante no circuito da pulsão, dá margem à formulação lacaniana de que a linguagem é o que intervém como uma espécie de intermediação entre sujeito e objeto, ao inserir uma distância entre gozo e corpo. Assim, não há encontro instintivo, porque o acesso direto ao objeto é negado desde o princípio, já que o significante faz um furo em toda tentativa de tomar o sujeito como correlato natural e harmônico de um objeto - algo que Lacan formaliza com seu matema da fantasia $[(\$ \diamond a)]$, no qual o sujeito, barrado pela linguagem, está sempre em um descompasso, em uma relação de desigualdade com o objeto que causa seu desejo.

Terceiro, porque isso é feito a partir da noção de objeto parcial, segundo a qual a pulsão não se ligaria a um objeto total, mas apenas a traços desse objeto, o que coloca em questão uma definição simplista da orientação sexual em termos de atração por homens, por mulheres, por ambos etc. Lacan ainda aprofundaria essa ideia ao retificar esse objeto parcial como objeto causa de desejo, objeto $a$, isto é, um objeto enigmático que atua como condição para o desejo, como no caso do paciente de Freud (1927/2017). Um estranho tipo de objeto que encontra, em cada um, uma marca, um trajeto singular, a partir dos vestígios de gozo que foram deixados pelo Outro em seu corpo. Com isso, Lacan depreende o caráter perverso, no sentido fetichista de gozar apenas de uma parte do corpo do Outro, presente em toda sexualidade humana, sempre desviante de uma suposta genitalidade natural.

Quarto, enfim, porque, em Lacan (1962-63/2005), trata-se de um desejo que não visa um objeto, mas que é, antes, causado por ele: o objeto $a$ só opera como causa, e não como visada do desejo; o brilho no nariz é causa, condição para o desejo, mas não é o brilho no nariz que é desejado. Assim, para cada sujeito o desejo encontra um elemento singular que o causa, seja um olhar, uma voz, um traço, em suma: um elemento destacável, muitas vezes imperceptível, que mobiliza o sujeito como desejante e o fisga em suas relações narcísicas com o semelhante. Seguindo o matema da fantasia [ $\$ \diamond a)]$, no encontro (sempre falho) com o objeto, o sujeito se torna desprovido de 
suas identificações simbólicas, dos significantes-mestres que o orientam no laço social. Afinal, na fantasia inconsciente, o sujeito aparece dividido, exilado de toda coerência identitária que a identificação a um significante-mestre $\left(\mathrm{S}_{1}\right)$ lhe forneceria.

Como consequência, ainda na fantasia, as coordenadas viris que orientam um sujeito quanto ao que é ser um homem (seus significantes-mestres) não são suficientes para garanti-lo quanto ao gozo. Na medida em que a fantasia demarca o fading, a evanescência do sujeito (\$) diante do encontro com o objeto $a$, as identificações de gênero $\left(S_{1}\right)$ que o sustentariam também se esvaem. Nessa esteira, é a própria noção de orientação sexual que se torna fraturada pela consideração da fantasia, pois esta coloca em questão o próprio lugar de onde o desejo toma forma, fazendo com que, no inconsciente, não haja, por exemplo, um homem que deseja uma mulher, mas sim um sujeito barrado que, em sua solidão, procura um objeto $a$ que fizesse as vezes de seu parceiro.

Uma vez que o inconsciente conduz cada ser falante a gozar de uma maneira radicalmente estranha aos parâmetros narcísicos do eu, o sujeito encontra aí um ponto de sua divisão: trata-se da angústia que o assola ao confrontar a singularidade de seu modo de gozo (por exemplo, a atração por certo brilho no nariz) com o universal das demandas de gênero (segundo as quais, no imperativo heterossexual, o homem deveria gozar de todas as mulheres). Se o saber do gênero busca orientar o desejo a partir do outro tomado como um objeto total (e.g.: eu, um homem, devo desejar mulheres), então suas coordenadas normativas se revelam insuficientes para lidar com a satisfação pulsional, na medida em que esta não se orienta pela imagem do semelhante, tomado como a forma completa de uma pessoa, mas, antes, pelo que constitui, para cada um, sua versão do "brilho no nariz" que causa seu desejo.

Assim, a pulsão não se liga ao envelope narcísico do semelhante [i $(a)]$, mas, antes, ao objeto $a$, de modo que as coordenadas normativas do gênero (segundo as quais o desejo dos homens deveria se orientar em direção a todas as mulheres) tornam-se incapazes de cernir a causa do desejo. A esse respeito, Lacan (1960/1998b) nos entrega um refinado catálogo de objetos $a$ passíveis de se ligar à satisfação pulsional objetos cujos suportes podem ser corpos dos mais variados gêneros, sem encontrar nenhum (gênero) que lhe seja próprio: "lábios, 'cerca dos dentes', borda do ânus, sulco peniano, vagina, fenda palpebral e até o pavilhão da orelha", juntamente com "mamilo, cíbalo, falo (objeto imaginário), fluxo urinário", "o fonema, o olhar, a voz - o nada" (p. 832). São esses objetos (entre outros tantos possíveis) que orientam, no inconsciente, a causa do desejo, mais do que qualquer atração por um gênero determinado que caracterizaria uma orientação sexual.

Nessa esteira, por instituir um modo de gozo avesso à satisfação instintiva, o inconsciente comparece como desarmônico e parasitário; ele não habita o ser falante sem toda sorte de inconvenientes, gerados pela insistência de um saber que o sujeito não sabe - o saber inconsciente -, que intervém em suas relações com o semelhante para não se prestar de nenhuma maneira a um "casamento feliz" (Lacan, 1973-1974/2016, p. 250). É por causa disso que o "mau encontro central está no nível do sexual” (Lacan, 1964/2008, p 68), já que, não havendo no psiquismo nada pelo que "o sujeito se pudesse situar como ser de macho ou ser de fêmea" (p. 200), o que vem em suplência a isso "fica entregue ao aleatório do campo do Outro. Fica entregue às explicações que se lhes deem" (p. 194). O que significa que não há, no ser falante, um saber a priori sobre o sexo, de forma que é o saber do gênero, advindo do campo do Outro, que fornecerá ao sujeito uma orientação quanto a sua posição sexuada.

Dessa construção lacaniana, podemos depreender que o gênero comparece como suplência à ausência de saber no real sobre o sexo (Lima, 2018). Como não há nenhuma determinação natural advinda da anatomia, é a linguagem que produzirá os destinos sexuados do sujeito, a partir da incidência de um saber sobre o gênero. Por conseguinte, "as vias do que se deve fazer como homem ou como mulher são inteiramente abandonadas ao drama, ao roteiro, que se coloca no campo do Outro" (Lacan, 1964/2008, p. 200). No entanto, a partir dessa transmissão do Outro, deriva-se para cada ser falante um modo de gozo singular, que pode entrar em conflito com as pretensões de universalidade da norma heterossexual. É nessa direção que Lacan (1972-1973/2008) desenvolverá mais tarde sua teoria da sexuação, que busca cernir as formas de satisfação na linguagem mais além das supostas determinações anatômicas sem se limitar aos destinos normativos que a cultura confere ao sujeito pela via do gênero.

Partindo do axioma de que não existe relação sexual (isto é, que não há uma programação simbólica 
a priori que garanta um encontro natural entre os sexos), Lacan (1972-1973/2008) sustenta que o ser falante encontra duas formas de gozar, isto é, de ratear na linguagem: uma, toda fálica, e outra, não-toda fálica (as quais o psicanalista nomeou, respectivamente, masculina e feminina). A forma toda fálica implica que o ser sexuado se posiciona no discurso por uma tentativa falha de se ancorar num universal, a partir da identificação a um ponto comum que uniria todos os pertencentes a dado conjunto. No campo dos homens, isso se daria pelo engodo fálico do órgão como atributo que reuniria o universo masculino (Lacan, 19711972/2012). Assim, a crença nos semblantes tende a fisgar quem se posiciona do lado todo fálico da sexuação, lado dito masculino (Miller, 2010).

Do outro lado, a forma não-toda fálica compõe outra maneira de gozar-ratear na linguagem, no que os sujeitos que aí se inserem fazem furo no universal, fazem objeção a ele, pela impossibilidade de constituírem qualquer universalização. Assim, o gozo não-todo apontaria para a singularidade de um arranjo que precisa se haver com a ausência de um significante para organizar esse gozo de forma universal. Por causa disso, é uma posição que suspeita dos semblantes como suficientes em matéria de gozo - na medida em que é não-toda regida pelo falo e pela castração -, ao engendrar um ponto de satisfação mais além da própria linguagem, um estranho gozo da ordem do inominável que não pode ser todo circunscrito pelo significante - o que compõe o lado dito feminino (Miller, 2010).

Vale lembrar que Lacan faz o movimento de desnaturalizar a sexuação ao ancorá-la em processos de inscrição na linguagem, de modo que não é por "nascer homem" que um sujeito seria todo fálico, tampouco por "nascer mulher" que um sujeito seria não-todo fálico. Pelo contrário, essa lógica é invertida: é pela sua posição no discurso que se poderá dizer do sujeito se ele se inscreve no lado fálico ou no lado não-todo fálico (Soler, 2005). Assim, a sexuação diz respeito ao modo com que cada ser falante aparelha seu corpo para o gozo, mais além das supostas determinações de sua anatomia, tentando se ancorar num universal (lado dito masculino) ou fazendo objeção a ele, apontando para sua singularidade (lado dito feminino).

Portanto, a sexuação se distribui entre duas formas de fracasso, duas formas de fazer fracassar a norma: "Não há relação sexual porque o gozo do Outro, tomado como corpo, é sempre inadequado - perverso de um lado, no que o Outro se reduz ao objeto $a-$ e do outro, eu direi louco, enigmático" (Lacan, 19721973/2008, p. 155). O gozo se revela, assim, como a relação perturbada que cada ser falante tem com o próprio corpo (Lacan, 1971-1972/2012), distribuído entre duas maneiras de se posicionar, com diferentes entradas para o gozo.

Por um lado, na vertente todo fálica, trata-se de procurar um objeto $a$, ficção neurótica nunca plenamente encontrada, que leva a um fading do sujeito (\$). Essa posição, mesmo sendo nomeada como masculina, não se restringe a escolhas feitas por homens, mas se estende a todas as formas de gozar do Outro como um objeto $a$, como vimos ao longo deste trabalho. Por outro lado, na vertente não-toda, trata-se de procurar o falo [Ф] como um elemento organizador na parceria amorosa, um elemento frente ao qual o pênis é sempre insuficiente. Mas essa posição congrega uma duplicidade que leva o ser falante a gozar também pela via do êxtase, do arrebatamento amoroso, da devastação pela via de uma fragmentação corporal que o falo não é capaz de conter completamente $[S(\mathbb{A})]$.

Sabemos que a terminologia com que Lacan nomeia essa partilha sexual, dividida entre o lado dito masculino e o lado dito feminino, gerou uma série de críticas por permanecer aparentemente referida ao binário normativo do gênero. Porchat (2014), por exemplo, afirma que, ao aceitar "a divisão binária entre as identidades 'homem' e 'mulher”, a psicanálise abre mão de sua radicalidade, mantendo uma terminologia tradicional que não questionaria a ideia de gênero (p. 79). Atento a esse tipo de crítica, Cossi (2018) argumentará que essa nomeação dos dois lados corresponderia apenas ao "aspecto performativo" da sexuação, sendo que, no fundo, todo sujeito pode circular entre os modos de gozo da tábua (p. 325).

Assim, não se trata de dois tipos de sujeito, mas de dois modos de circulação, de posicionamento de um mesmo sujeito em relação à função fálica (Cossi, 2018). Podemos então pensar que essa nomeação como "masculino" e "feminino" constitui uma tentativa de Lacan de cernir as formas historicamente constituídas de distribuir os gêneros entre os dois modos de gozo. Dessa maneira, "homem" e "mulher" seriam semblantes que a cultura nos oferece para nomear as posições de gozo que podem orientar um sujeito. Trata-se de performativos, que dependem de uma assunção subjetiva e de repetições ritualizadas para funcionarem como uma orientação precária no discurso. 
Ao tratar de "homem" e "mulher" como semblantes que dizem respeito às diferentes posições discursivas que um ser falante pode assumir, Lacan (19721973/2008) acaba por produzir um gesto subversivo numa direção ainda pouco explorada. Quando ele afirma, a partir dos modos de gozo, que a histérica é homem e São João da Cruz é mulher, o psicanalista desestabiliza os significados correntes de "homem" e "mulher", gerando um efeito queer na sexuação, precisamente por se servir do aspecto performativo de tais nomeações. Nesse contexto, Lacan se serve dos performativos do gênero (homem e mulher) num sentido que os desloca de sua designação tradicional (pautada na anatomia). Ao fazer isso, ele desapropria as anatomias das posições sexuadas que lhes seriam tradicionalmente respectivas: nascer com pênis não transforma alguém em homem; ter um pênis não implica ocupar uma posição masculina - e vice-versa. Assim, uma vez que a sexuação apresenta duas formas de falha lógica em relação ao gozo, então não há posição sexuada própria ou adequada a uma anatomia.

Mas, se quisermos extrair as consequências da crítica de Porchat (2014) quanto à terminologia, devemos também considerar que os modos de gozo fálico e não-todo fálico não estão necessariamente articulados aos semblantes (significantes-mestres) de "homem" e "mulher". Torna-se, portanto, tarefa de cada ser falante inventar sua maneira de vincular um semblante ao seu modo de gozo, seja recorrendo à tradição, seja produzindo uma composição inédita a partir dos gêneros não-inteligíveis: um sujeito que goza como todo fálico a partir do semblante de "lésbica butch" ou de "homem trans", um sujeito que goza como não-todo por meio do semblante da "bicha afeminada" ou da "drag queen", entre outras tantas combinações possíveis, artesanalmente compostas no um a um.

\section{Desdobramentos: a psicanálise e a matriz sexo-gênero-orientação sexual}

Ao longo do texto, tentamos indicar algumas das ferramentas que a psicanálise nos fornece para pensar a sexualidade mais além da matriz sexo-gênero-orientação sexual, amplamente utilizada nos discursos contemporâneos da psicologia - a exemplo da cartilha mencionada no começo de nosso trabalho (Conselho Regional de Psicologia - Bahia, 2019). Sem desconsiderar a importância desse tipo de material para promover o respeito à diversidade de gêneros e sexualidades, buscamos reunir aqui algumas das contribuições que a clínica psicanalítica pode oferecer para esse debate a partir de outra perspectiva, orientada pela singularidade do inconsciente.

Partindo da psicanálise, podemos tentar nuançar, por exemplo, a noção de orientação sexual, uma vez que, no campo do desejo, não se trata apenas de sentir-se atraído por pênis, por vaginas ou por ambos, tampouco apenas por pessoas de um gênero, de outro ou de vários. É preciso, antes, considerar o fato de que a pulsão é parcial, ela não se liga a representações de objetos totais, a formas determinadas de uma pessoa, mas, antes, a traços, restos e/ou resíduos redutíveis a um objeto $a$. Com esse objeto, o desejo se torna referido a algo que excede a orientação sexual, ultrapassando a referência do gênero (pessoas, objetos totais) para pensar a atração sexual. Afinal, nada há no psiquismo que permita orientar o sujeito quanto a seu ser de macho ou ser de fêmea, de modo que, na linguagem, não sabemos o que fazer com isso.

$\mathrm{Na}$ ausência de um saber a priori sobre o sexo, Freud (1914/1996) nos esclarece que a escolha de objeto pode se dar a partir de dois modos de investimento: a escolha narcísica e a escolha por apoio. De um lado, se alguém ama conforme o tipo narcisista, ela ama a) o que ela própria é (isto é, ela mesma); b) o que ela própria foi; c) o que ela própria gostaria de ser; ou d) alguém que foi uma vez parte dela mesma. De outro lado, se alguém faz sua escolha de objeto por apoio, ela ama a) a mulher que a alimenta; b) o homem que a protege; ou c) os substitutos que tomam seu lugar (Freud, 1914/1996). Assim, mesmo um homem que se diga heterossexual não tem interesse por todas as mulheres; seu interesse se volta apenas para algumas delas, por traços bem específicos. No desejo, não se trata de um objeto qualquer, mesmo que qualquer objeto possa estar nesse lugar de causa para um sujeito.

Se Freud fala da escolha de objeto, Lacan avança e nos permite pensar na escolha de um objeto $a$, que configura uma orientação sexuada para um sujeito ao constituir o estilo de sua causa de desejo, orquestrada pela fantasia. No entanto, esse circuito sempre deixa um resto a desejar, um resto real que permanece encoberto pela imagem narcísica do semelhante $[\mathrm{i}(a)]-$ resíduo que nos sinaliza a angústia de lidar com a estranheza íntima que parasita o gozo. Esse ponto, opaco como um brilho no nariz, revela o sem sentido subjacente ao sexo, que os semblantes da cultura buscam velar ao tentar impor a cis-heterossexualidade como norma para a satisfação (Lima, 2018). 
De maneira similar, mesmo conservando sua importância política, a noção de "identidade de gênero" parece portar, em seu fundo, uma esperança na coincidência de si consigo mesmo, ao fornecer um significante que conseguiria designar efetivamente $o$ ser do sujeito. A psicanálise teria aí uma dupla objeção: a) do ponto de vista da linguagem, a relação dos significantes é sempre diferencial, e não identitária, apenas estabelecida a partir de sua diferença com os outros significantes $\left(\mathrm{S}_{1}-\mathrm{S}_{2}\right)$; e b) o sujeito, barrado, nunca equivale aos significantes que vêm representá-lo. A identidade do Um, pressuposta na identidade de gênero, nunca pode coincidir consigo mesma, pois a divisão subjetiva (\$) não permite uma reconciliação completa entre o eu e o sujeito.

Como consequência, "homem", "mulher" e outras pretensas identidades não passam de significantes, sem nenhum significado a priori; por isso, dependem sempre de um sujeito que os assuma discursivamente, reconhecendo neles um traço de seu gozo, mais além dos sentidos imaginários que possam aí se vincular. Nessa direção, o gênero não é mais concebido como uma identidade de si consigo mesmo, mas antes como um semblante, um significante-mestre $\left(\mathrm{S}_{1}\right)$ que representa o sujeito no laço social. Assim, cada ser falante deve compor sua forma de "ser dito homem", "ser dito mulher" ou de articular a outros semblantes o gozo fálico e/ou o gozo não-todo. Disso depreendemos que a sexuação implica uma maneira singular de coordenar um semblante ao seu modo de gozar da castração.

Partindo dessas contribuições da psicanálise, cumpre observar que o objeto $a$ e a teoria da sexuação permitem pensar a sexualidade mais além da matriz sexo-gênero-orientação sexual que os saberes contemporâneos têm nos oferecido. Com essas ferramentas analíticas, é possível conceber o desejo sem referi-lo à forma completa de uma pessoa e localizar o gênero menos como uma identidade fixa do que como um semblante, um significante-mestre que representa o sujeito no discurso. Também tentamos mostrar o interesse da teoria psicanalítica por cernir algo da subjetividade que não é completamente regulado pelas normas sociais, por meio dos modos de gozo fálico e não-todo fálico. Tratou-se de, com isso, buscar resgatar alguns dos aportes fornecidos pela psicanálise aos debates contemporâneos sobre gênero e sexualidade, na esteira de autores como Ambra (2016), Quinet (2016), van Haute e Geyskens (2016), Lima (2018) e Cossi (2018).

Além disso, a despeito dos desencontros entre a teoria psicanalítica e os saberes contemporâneos sobre gênero e sexualidade, o trabalho crítico de autoras como Gallop (1988/2001), Butler (1990/2015), Arán (2009) e Porchat (2014) deve nos servir precisamente para manter esse debate em movimento, produzindo uma reorganização da psicanálise a partir das exigências clínicas colocadas pela subjetividade de nossa época. Se levarmos a sério o caráter não-todo subversivo da teoria psicanalítica (Ambra, 2016), escutar essas críticas pode nos ajudar a sustentar a vertente subversiva do campo freudiano, evitando a reiteração de arranjos normativos herdados do social. Ademais, partindo da crítica de Porchat (2014) à terminologia lacaniana, nossa leitura da sexuação nos conduziu a melhor situar os semblantes do gênero em sua (não-)relação com os modos inconscientes de gozo, avessos às identidades socialmente codificadas.

Nesse sentido, essas elaborações sobre a sexuação nos indicam que um psicanalista deve estar advertido dos saberes contemporâneos sobre gênero e sexualidade, mas precisa também, sem desconsiderá-los, estar avisado da estranheza da satisfação pulsional que se manifesta em cada um à sua maneira, mais além dos regimes normativos de identidade. Isso implica dar lugar às invenções de cada sujeito para lidar com aquilo do seu gozo que não se submete às normas sociais, a partir do seu modo próprio de coordenar um semblante a uma forma inconsciente de satisfação. Tudo isso significa, ainda em nosso tempo, sustentar a posição de um pioneirismo subversivo - pois importa menos o que fizeram os grandes autores do passado do que o que faremos nós com aquilo que deles herdamos. 


\section{Referências}

Ambra, P. (2016). A psicanálise é cisnormativa? Palavra política, ética da fala e a questão do patológico. Periódicus, 5(1), 101-120. https://portalseer.ufba.br/index.php/revistaperiodicus/article/view/17179/11336

Arán, M. (2009). A psicanálise e o dispositivo diferença sexual. Estudos Feministas, 17(3), 653-673. https://periodicos. ufsc.br/index.php/ref/article/view/S0104-026X2009000300002/12121

Beauvoir, S. de (1989). The second sex. New York: Vintage Books. (Trabalho original publicado em 1949)

Butler, J. (2015). Problemas de gênero: feminismo e subversão da identidade (9a ed.). Rio de Janeiro, RJ: Civilização Brasileira. (Trabalho original publicado em 1990)

Conselho Regional de Psicologia - Bahia (2019). Psicologia, sexualidades e identidades de gênero: guia de referências técnicas e teóricas. Salvador, BA. https://www.crp03.org.br/wp-content/uploads/2019/01/CRP03-CartilhaPsicologia-Sexualidades-e-Identidades-de-G\%C3\%AAnero-1.pdf

Cossi, R. K. (2018). Lacan e o feminismo: a diferença dos sexos. São Paulo, SP: Annablume.

Ferenczi, S. (1992). O homoerotismo: nosologia da homossexualidade masculina. In S. Ferenczi, Psicanálise II (pp. 117-129). São Paulo, SP: Martins Fontes. (Trabalho original publicado em 1911)

Freud, S. (1996) Três ensaios sobre a teoria da sexualidade. In Edição standard brasileira das obras psicológicas completas de Sigmund Freud (J. Salomão, Trad., Vol. 7, pp. 124-230). Rio de Janeiro, RJ: Imago. (Trabalho original publicado em 1905)

Freud, S. (1996). Sobre o narcisismo: uma introdução. In Edição standard brasileira das obras psicológicas completas de Sigmund Freud (J. Salomão, Trad., Vol. 14, pp. 81-110). Rio de Janeiro, RJ: Imago. (Trabalho original publicado em 1914)

Freud, S. (2017). Sobre a psicogênese de um caso de homossexualidade feminina. In Obras incompletas de Sigmund Freud: Neurose, psicose, perversão (Vol. 5, pp. 157-192). Belo Horizonte, MG: Autêntica. (Trabalho original publicado em 1920).

Freud, S. (2017). Fetichismo. In Obras incompletas de Sigmund Freud: Neurose, psicose, perversão (Vol. 5, pp. 315-325). Belo Horizonte, MG: Autêntica. (Trabalho original publicado em 1927)

Freud, S. (2018). Feminilidade. In Obras incompletas de Sigmund Freud: Amor, sexualidade, feminilidade (Vol. 7, pp. 313-348). Belo Horizonte, MG: Autêntica. (Trabalho original publicado em 1933)

Freud, S. (2018). Carta a uma mãe preocupada com a homossexualidade de seu filho. In Obras incompletas de Sigmund Freud: Amor, sexualidade, feminilidade (Vol. 7, pp. 349-352). Belo Horizonte, MG: Autêntica. (Trabalho original publicado em 1935)

Gallop, J. (2001). Além do falo. Cadernos Pagu, 16, 267-287. (Trabalho original publicado em 1988). http://www.scielo.br/pdf/cpa/n16/n16a12.pdf

Lacan, J. (1998). A significação do falo. In Escritos (pp. 692-703). Rio de Janeiro, RJ: Zahar. (Trabalho original publicado em 1958)

Lacan, J. (1998a). Diretrizes para um congresso sobre a sexualidade feminina. In Escritos (pp. 734-745). Rio de Janeiro, RJ: Zahar. (Trabalho original publicado em 1960)

Lacan, J. (1998b). Subversão do sujeito e dialética do desejo no inconsciente freudiano. In Escritos (pp. 807-842). Rio de Janeiro, RJ: Zahar. (Trabalho original publicado em 1960). Lacan, J. (2005). O seminário, livro 10: a angústia, 1962-1963. Rio de Janeiro, RJ: Zahar.

Lacan, J. (2008). O seminário, livro 11: os quatro conceitos fundamentais da psicanálise, 1964. Rio de Janeiro, RJ: Zahar.

Lacan, J. (2008). O seminário, livro 20: mais, ainda, 1972-1973. Rio de Janeiro, RJ: Zahar.

Lacan, J. (2012). O seminário, livro 19: ...ou pior, 1971-1972. Rio de Janeiro, RJ: Zahar.

Lacan, J. (2016). O seminário, livro 21: os não-tolos vagueiam, 1973-1974. Salvador, BA: Espaço Moebius.

Lima, V. M. (2018). O gênero binário como semblante de relação sexual: entre psicanálise lacaniana e teoria queer. Mosaico: Estudos em Psicologia, 6(1), 20-35. https:// periodicos.ufmg.br/index.php/mosaico/article/view/12222

Miller, J.-A. (2010). Mulheres e semblantes II. Opção lacaniana Online, 1, 1-25. http://www.opcaolacaniana.com.br/ pdf/numero_1/Mulheres_e_semblantes_II.pdf 
Porchat, P. (2014). Psicanálise e transexualismo: descontruindo gêneros e patologias com Judith Butler. Curitiba, PR: Juruá.

Quinet, A. (2016). Homofobias psicanalíticas na psicologização do Édipo. Stylus: Revista de Psicanálise, 33, 191-199. http://pepsic.bvsalud.org/pdf/stylus/n33/n33a15.pdf

Soler, C. (2005). O que Lacan dizia das mulheres. Rio de Janeiro, RJ: Zahar.

Van Haute, P., \& Geyskens, T. (2016). Psicanálise sem Édipo? Uma antropologia clínica da histeria em Freud e Lacan. Belo Horizonte, MG: Autêntica.

Zupančič, A. (2008). Sexualidade e ontologia. Revista Estudos Lacanianos, 1(2), 311-326. http://pepsic.bvsalud.org/ $\mathrm{pdf} / \mathrm{rel} / \mathrm{vln} 2 / \mathrm{vln} 2 \mathrm{a} 10 . \mathrm{pdf}$

\section{Vinícius Moreira Lima}

Psicanalista. Mestrando em Estudos Psicanalíticos pelo Programa de Pós-Graduação em Psicologia da Universidade Federal de Minas Gerais (UFMG) (2020-2022), Belo Horizonte - MG. Brasil. Graduação em Psicologia (UFMG). Bolsista de mestrado do CNPq. Ex-bolsista de iniciação científica pelo PIBIC/CNPq.

E-mail:vmlima6@gmail.com

(1) http://orcid.org/0000-0002-4253-8154

\section{Ângela Maria Resende Vorcaro}

Psicanalista. Membro da Association Lacanienne Internationale. Doutora em Psicologia Clínica pela Pontifícia Universidade Católica de São Paulo (PUC-SP). Professora do Departamento de Psicologia da Universidade Federal de Minas Gerais, Belo Horizonte - MG. Brasil.

E-mail: angelavorcaro@uol.com.br

(1) https://orcid.org/0000-0002-6538-8646

Endereço para envio de correspondência:

Universidade Federal de Minas Gerais. Avenida Antônio Carlos, 6627, Bairro Pampulha. CEP: 31270-901.

Belo Horizonte - MG. Brasil.

Recebido 26/02/2018

Aceito 29/04/2019

Received 26/02/2018

Approved 29/04/2019

Recibido 26/02/2018

Aceptado 29/04/2019 
Como citar: Lima, V. M., \& Vorcaro, A. M. R. (2020). O Pioneirismo Subversivo da Psicanálise nos Debates de Gênero e Sexualidade. Psicologia: Ciência e Profissão, 40, 1-13.

https://doi.org/10.1590/1982-3703003192180

How to cite: Lima, V. M., \& Vorcaro, A. M. R. (2020). The Subversive Pioneer nature of Psychoanalysis in Discussion Surrounding Gender and Sexuality. Psicologia: Ciência e Profissão, 40, 1-13.

https://doi.org/10.1590/1982-3703003192180

Cómo citar: Lima, V. M., \& Vorcaro, A. M. R. (2020). El Pionerismo Subversivo del Psicoanálisis en los Debates sobre Género y Sexualidad. Psicologia: Ciência e Profissão, 40, 1-13.

https://doi.org/10.1590/1982-3703003192180 